\title{
Tamanho relativo dos órgãos internos e do trato gastrintestinal de bovinos indubrasil e mestiços leiteiros em fase de engorda
}

\author{
Relative size of the internal organs and gastrointestinal tract of dairy crossbreeds and zebu \\ steers in fattening
}

\author{
Alfredo Acosta Backes ${ }^{\mathrm{I}}$ Mário Fonseca Paulino ${ }^{\mathrm{II}}$ Dorismar David Alves $^{\mathrm{III}}$ \\ Sebastião de Campos Valadares Filho ${ }^{\text {IV }}$
}

\section{RESUMO}

Utilizaram-se 12 bovinos machos castrados, com peso vivo médio de $276 \mathrm{~kg}$, sendo quatro indubrasil e oito mestiços leiteiros (quatro $1 / 2$ sangue HolandêsxGir e quatro $1 / 2$ sangue HolandêsxGuzerá). Foram pesados e distribuídos em dois tratamentos (indubrasil e mestiços leiteiros), em fase de engorda. Os animais foram avaliados até atingirem $480 \mathrm{~kg}$ de peso vivo. $O$ volumoso utilizado foi o feno de capim Tifton 85 (Cynodon dactylon). Por ocasião do abate foram coletadas amostras de rúmen, retículo, omaso, abomaso e intestinos, após o seu esvaziamento e limpeza, obtendo-se ainda os pesos e amostras de sangue, couro, pés, cabeça, fígado, rins, pulmões, língua, baço e gordura interna (mesentério e gorduras perirenal e pericardíaca). O peso do corpo vazio (PCVZ) foi obtido pela soma dos pesos da carcaça, sangue, couro, pés, rabo, vísceras e órgãos. Animais da raça indubrasil apresentam o conjunto cabeça-pés-couro mais pesado do que animais mestiços leiteiros. Animais mestiços leiteiros e indubrasil, em fase de engorda, não apresentam diferenças significativas quanto ao peso total de intestinos e órgãos. Animais mestiços leiteiros apresentam, em fase de engorda, maiores proporções de gordura interna do que animais indubrasil.

Palavras-chave: carcaça, couro, gordura mesentérica.

\section{ABSTRACT}

Twelve steers have been used, when they had average live weight of $276 \mathrm{~kg}$, being four indubrasil and eight dairy crossbreeds (four crossbreeds HolsteinxGir and four HolsteinxGuzera). They have been weighted and distributed into two treatments (indubrasil and dairy crossbreeds), in phase fattening. The animals were studied up to $480 \mathrm{~kg}$ of live weight. Grass hay Tifton 85 (Cynodon dactylon) have been used as feedstuff. After slaughtering samples of rumen, reticulum, omasum, abomasum and intestines have been collected after emptying and cleaning. Weight and samples values of blood, leather, feet, head, liver, kidneys, lung, tongue, spleen and internal fat (mesenterium plus perirenal and pericardia fats) have been collected. Empty body weight (EBW) have been obtained by summing weights of carcass, blood, leather, feet, tail, intestines and organs. The group head-foot-leather of indubrasil steers have been heaver than in dairy crossbreeds. The animals indubrasil and dairy crossbreeds, in fattening phase, have not presented significant differences for total weight of intestines and organs. The animals dairy crossbreeds present, in fattening phase, higher fat proportions intern than indubrasil animals.

Key words: carcass, leather, mesenterium fat.

\section{INTRODUÇÃO}

A avaliação do tamanho relativo dos órgãos é de extrema importância devido possuir influência direta no rendimento de carcaça e sobre a exigência de energia para mantença. As partes não-integrantes da carcaça variam, em peso, de acordo com a raça, o estádio de maturidade e o nível nutricional (VELOSO et al., 2002). Conforme JORGE et al. (1999), essa variação influencia diretamente o rendimento de carcaça, as exigências de mantença e o ganho de peso. As funções primárias do trato gastrintestinal e seus órgãos acessórios são a digestão e a absorção de nutrientes essenciais para os processos metabólicos. Todavia, segundo

IDepartamento de Zootecnia, Fundação Universidade Federal de Sergipe (UFS), 49100-000, São Cristovão, SE, Brasil. E-mail: abackes2003@yahoo.com.br. Autor para correspondência.

IIDepartamento de Zootecnia, Universidade Federal de Viçosa (UFV), Viçosa, MG, Brasil.

IIIZootecnista, UNIMONTES, Montes Claros, MG, Brasil.

${ }^{\mathrm{IV}}$ Departamento de Zootecnia, UFV, Viçosa, MG, Brasil. 
SIGNORETTI et al. (1999), poucas pesquisas têm sido feitas por parte dos nutricionistas de ruminantes sobre os aspectos quantitativos das partes não-integrantes da carcaça.

As raças com ascendência leiteira apresentam maior peso relativo do rúmen-retículo, fígado, coração, pulmões e baço que as raças de corte (CARVALHO et al., 2003). FERREL et al. (1976) observaram que os intestinos, fígado, coração e rins de novilhas leiteiras (Jersey) são, proporcionalmente, maiores que os de novilhas de corte (Hereford). Além disso, verificaram que o total de energia para mantença exigida pelo tecido muscular é menor que o da energia exigida pelos órgãos internos, isso explicaria as maiores exigências para mantença em animais com aptidão leiteira. Os animais da raça Holandês apresentam maior peso do trato gastrintestinal (TGI) vazio (estômago e intestinos) que as raças especializadas para corte (PERON et al, 1993). Isso ocorre, provavelmente, conforme SIGNORETTI et al. (1999), em virtude da seleção ter sido direcionada, principalmente, para produção de leite o que exige maior consumo de alimentos.

O regime alimentar e o peso de abate exercem influência sobre as proporções das diferentes partes do corpo não-integrantes da carcaça (JORGE et al., 1999). Trabalhando com bovinos (Nelore e mestiços Holandês) abatidos com pouco peso, com bovinos em restrição alimentar e com bovinos em alimentação ad libitum, PERON et al. (1993) encontraram maior peso dos órgãos internos para os mestiços da raça Holandês do que para os animais nelore. Esses autores também observaram que a restrição alimentar não ocasionou redução dos pesos do pulmão e coração. Porém, verificaram que o fígado e os componentes do trato gastrintestinal diminuíram de peso. Os resultados mostraram que o coração e o pulmão possuem prioridades na utilização dos nutrientes. Conforme JORGE et al. (1999), jejum de dois dias pode resultar em perda de peso do fígado de até $25 \%$. O fígado, coração, rins, glândula mamária e tecidos do trato gastrintestinal estão entre aqueles com maior atividade metabólica em bovinos.

Os pesos de cabeça, pés e couro representam de 15 a $17 \%$ do peso vivo do animal. Assim, quanto menor for o peso desses componentes, maior será o rendimento de carcaça (CARVALHO et al., 2003). Conforme esses autores o peso relativo do couro em relação ao PCVZ é menor em novilhos Holandês do que em raças de corte. Trabalhando com as raças Gir, Guzerá, Nelore e Tabapuã, JORGE et al. (1999) observaram que o conjunto cabeça-pés-couro foi maior para os animais Nelore do que para animais Gir e
Tabapuã. Segundo os referidos autores, os zebuínos têm apresentado, de maneira geral, maiores valores para esse conjunto do que animais europeus e mestiços europeu-zebu. Isso estaria relacionado a um maior tamanho relativo do couro, ou seja, presença de giba e barbela mais desenvolvidas.

As diferenças nas exigências de energia para mantença entre grupos genéticos podem ser, em parte, explicadas por diferenças no tamanho de seus órgãos, que são maiores nos taurinos do que nos zebuínos (SILVA et al., 2002). Animais com aptidão leiteira possuem exigências energéticas de mantença maiores do que as raças para corte. Isso pode ser parcialmente explicado pelo fato de que a quantidade de energia gasta pelos órgãos internos como coração, fígado, rins e intestinos, é maior que a energia gasta pelo tecido muscular, sendo que os animais de corte possuem menor massa de órgãos internos. Os tecidos viscerais consomem cerca de $50 \%$ da energia destinada para mantença, enquanto os músculos, embora apresentem maior massa no corpo vazio dos animais, consomem apenas $23 \%$ do total da energia para mantença. Esse fato acontece porque certos tecidos viscerais como o trato gastrintestinal e o fígado, possuem maior turnover protéico que o músculo esquelético (SILVA et al., 2002).

Em raças com aptidão leiteira, os maiores depósitos de gordura encontram-se nos componentes não-carcaça, diferentemente das tradicionais raças de corte, em que os depósitos periféricos são mais pronunciados, ocasionando menor exigência para mantença desses últimos (VÉRAS et al., 2001). Ainda sobre o local de deposição de gordura, parece que animais leiteiros e taurinos possuem maior deposição de gordura interna do que os animais zebuínos, os quais parecem possuir maior deposição de gordura externa. O local de deposição das reservas de gordura é um fator que possui substancial impacto sobre as exigências de energia de mantença de bovinos. Portanto, a análise do teor dessa gordura torna-se de suma importância. Segundo PERON et al. (1993), os zebuínos apresentam menores depósitos de gordura interna, os quais são metabolicamente mais ativos e, portanto, possuem influência nas exigências de mantença. Assim, maiores teores de gordura interna, no caso dos taurinos, influenciariam na maior exigência energética de mantença.

Objetivou-se, no presente trabalho, avaliar o tamanho relativo dos órgãos internos e do trato gastrintestinal de bovinos indubrasil e mestiços leiteiros, em fase de engorda. 


\section{MATERIAL E MÉTODOS}

O experimento foi realizado nas dependências do laboratório de Nutrição Animal do Departamento de Zootecnia da Universidade Federal de Viçosa, em Viçosa (MG). Foram utilizados 12 bovinos machos castrados, com peso médio de $276 \mathrm{~kg}$, sendo quatro indubrasil e oito mestiços leiteiros (quatro $1 / 2$ sangue HolandêsxGir e quatro $1 / 2$ sangue HolandêsxGuzerá). Os animais foram pesados e distribuídos em dois tratamentos (zebu e mestiços leiteiros), em fase de engorda, em delineamento inteiramente casualizado com seis repetições. Os animais foram avaliados até $480 \mathrm{~kg}$ de peso vivo. A relação volumoso:concentrado da dieta foi de 60:40. O volumoso utilizado foi o feno de capim tifton 85 (Cynodon dactylon). A ração foi formulada com base no NRC (1996), contendo 2,77Mcal de EM kg ${ }^{-1}$ e 84, 13 e 52\% de MS, PB e FDN, respectivamente. Na tabela 1, são mostradas as proporções dos ingredientes que formam o concentrado.

Os animais foram pesados a cada 28 dias. A alimentação foi fornecida uma vez ao dia (pela manhã) e ajustada de forma que sempre houvesse sobra de $10 \%$ do ofertado diariamente, sendo a água fornecida permanentemente aos animais.

Antes do abate os animais foram submetidos a um período médio de jejum de sólidos de 16 horas. Por ocasião do abate foram coletadas amostras do rúmen-retículo, omaso, abomaso e intestinos após o seu esvaziamento e limpeza, obtendo-se ainda os pesos e amostras de sangue, couro, pés, cabeça, fígado, coração, rins, pulmões, língua, baço e gordura cavitária (mesentério mais gorduras perirenal e pericardíaca).

O peso do corpo vazio (PCVZ) dos animais foi obtido da seguinte forma:

$\mathrm{PCVZ}=\mathrm{PV} \quad-$ (peso da carcaça quente+sangue+couro+pés+rabo+vísceras vazias e

Tabela 1 - Proporções dos ingredientes utilizados nos concentrados, expressas em função da matéria seca.

\begin{tabular}{lc}
\hline Ingredientes & Proporção (\%) \\
\hline Fubá de milho & 80,82 \\
Farelo de soja & 17,83 \\
Uréia & 0,45 \\
Sulfato de amônio & 0,06 \\
Sal (NaCl) & 0,36 \\
Fosfato bicálcico $_{\text {Premix mineral }^{1}}^{0,43}$ \\
\hline
\end{tabular}

${ }^{1}$ Sulfato de Zinco (80\%), Sulfato de Cobre (19\%), Sulfato de Cobalto (0,25\%), Selenito de Sódio (0,25\%) e Iodato de Potássio $(0,5 \%)$. limpas (constituídas, neste trabalho, pelo intestino delgado, intestino grosso, gordura interna, mesentério, aparas, rúmen, retículo, omaso e abomaso) + órgãos limpos (constituído pelo coração, rins, baço, fígado, pulmões, pâncreas, língua, traquéia, esôfago, pênis, bexiga e diafragma)).

Os resultados foram interpretados por meio de análises de variância, teste "F" e teste de comparação de médias (teste "t" a 1 e a $5 \%$ de probabilidade), utilizando-se o Sistema de Análises Estatísticas e Genéticas-SAEG (UFV, 1995).

\section{RESULTADOS E DISCUSSÃO}

Os pesos médios, expressos em quilograma (kg) e em porcentagem do peso do corpo vazio (PCVZ), de cabeça, pés, couro e seu conjunto, rabo, sangue, intestino delgado e grosso e o conjunto desses dois últimos (IDG), para animais mestiços leiteiros e zebu, são mostrados na tabela 2 . Observa-se que os animais indubrasil apresentaram couro e pés $(P<0,05)$ mais pesados do que os mestiços leiteiros, sendo os valores, em $\mathrm{kg}$, e em porcentagem do PCVZ. Esses componentes, juntamente com o maior valor numérico de cabeça, podem ter influenciado na diferença significativa no conjunto cabeça-pés-couro $(\mathrm{P}<0,05)$, que foi maior para os animais zebu. Segundo CARVALHO et al. (2003), o peso relativo do couro é maior em raças para corte do que em raças leiteiras Holandês, estando de acordo com os resultados obtidos no presente trabalho. JORGE et al. (1999), observaram que animais Nelore apresentaram maior peso do conjunto cabeça-pés-couro que animais mestiços leiteiros, corroborando com os resultados deste trabalho. Segundo JORGE et al. (1999), os zebuínos têm apresentado, de maneira geral, maiores valores do conjunto cabeça-pés-couro que animais europeus e mestiços europeu-zebu, o que estaria relacionado à presença de giba e barbelas mais desenvolvidas. O rendimento de carcaça é influenciado diretamente pelos componentes do conjunto cabeçapés-couro, isto é, quanto maior for o peso desse conjunto, menor o rendimento de carcaça. Porém, ALVES (2004), não observou diferença para rendimento de carcaça quente em relação ao peso corporal vazio, entre mestiços leiteiros (61,35\%) e zebu (61,48\%), mesmo com o conjunto cabeça-pés-couro sendo maior para zebu.

Os componentes rabo e sangue não apresentaram diferenças entre os grupos raciais. SILVA et al. (2002), utilizando animais da raça Nelore, encontraram valores levemente inferiores, para os referidos componentes, aos encontrados no presente trabalho. 
Tamanho relativo dos órgãos internos e do trato gastrintestinal de bovinos indubrasil e mestiços leiteiros...

Tabela 2 - Médias dos pesos de cabeça, pés, couro, conjunto cabeça-pés-couro, rabo, sangue, intestino delgado (ID), intestino grosso (IG) e do total de intestino (IDG), expressos em kg e em porcentagem do peso do corpo vazio (\% PCVZ), e o coeficiente de variação (CV), em percentagem, em animais mestiço leiteiro e zebu, em fase de engorda.

\begin{tabular}{|c|c|c|c|c|c|c|}
\hline Itens & $\begin{array}{c}\text { Mestiços leiteiros } \\
\text { kg }\end{array}$ & $\begin{array}{l}\text { Indubrasil } \\
\qquad \mathrm{kg}\end{array}$ & CV\% & $\begin{array}{c}\text { Mestiços leiteiros } \\
\text { \% PCVZ }\end{array}$ & $\begin{array}{l}\text { Indubrasil } \\
\text { \% PCVZ }\end{array}$ & $\mathrm{CV} \%$ \\
\hline Cabeça & 13,012 a & $14,675 \mathrm{a}$ & 13,50 & $3,701 \mathrm{a}$ & 3,774 a & 7,15 \\
\hline Pés & 8,875 b & $11,225 \mathrm{a}$ & 11,25 & $2,553 \mathrm{~b}$ & $2,883 \mathrm{a}$ & 10,35 \\
\hline Couro & $35,287 \mathrm{~b}$ & 42,700 a & 14,02 & 8,877 b & 10,987 a & 12,17 \\
\hline Cabeça-pés-couro & $57,175 \mathrm{~b}$ & 68,600 a & 12,12 & $15,131 \mathrm{~b}$ & 17,644 a & 11,19 \\
\hline Rabo & 1,336 a & $1,424 \mathrm{a}$ & 7,85 & 0,337 a & 0,369 a & 6,80 \\
\hline Sangue & 11,747 a & 13,091 a & 8,08 & 4,630 a & 4,851 a & 8,29 \\
\hline ID & 5,392 a & 4,847 a & 10,11 & 1,363 a & $1,250 \mathrm{a}$ & 9,32 \\
\hline IG & 3,465 a & 3,484 a & 11,65 & 0,871 a & 0,899 a & 7,52 \\
\hline IDG & $8,857 \mathrm{a}$ & 8,331 a & 13,20 & $2,234 \mathrm{a}$ & $2,149 \mathrm{a}$ & 10,11 \\
\hline
\end{tabular}

Médias, nas linhas, seguidas de letras distintas são diferentes $(\mathrm{P}<0,05)$ pelo teste Tukey.

O peso total dos intestinos (IDG) limpos, não apresentou diferença significativa entre os grupos raciais. Em geral, animais com sangue da raça Holandês possuem intestinos mais desenvolvidos, em conseqüência da seleção ser voltada para produção de leite o que exige maior consumo de MS, embora, no presente trabalho, esta diferença não tenha sido significativa. JORGE et al. (1999), utilizando raças zebuínas e mestiços leiteiros, também não observaram diferenças significativas, quanto ao peso total dos intestinos, entre os grupos raciais.

As médias dos pesos, em $\mathrm{kg}$ e em porcentagem do PCVZ, de rins, baço, coração, pulmões, fígado e língua dos animais dos diferentes grupos raciais, encontram-se na tabela 3. Observa-se que para todos os componentes dos animais indubrasil foram, em valores absolutos, mais leves, tanto em kg quanto em porcentagem do PCVZ. Em termos de prioridade de nutrientes, principalmente no decorrer do desenvolvimento corporal, os resultados têm mostrado que os órgãos coração, baço e pulmões são os componentes com maior prioridade, conforme relatos de vários autores (PERON et al., 1993; JORGE et al., 1999; VÉRAS et al., 2001). O fígado participa ativamente no metabolismo dos nutrientes, sendo considerado como de elevada taxa metabólica (OWENS et al., 1993), porém, neste trabalho, o fígado dos animais mestiços foi somente mais pesado em valores absolutos, não havendo diferença significativa.

Na tabela 4, estão as médias dos pesos, em $\mathrm{kg}$ e em porcentagem do PCVZ, dos diferentes componentes do estômago, mesentério e gordura interna (perirenal e pericardíaca) em animais mestiços leiteiros e zebu. O conjunto estômago (rúmen-retículoomaso-abomaso) não apresentou diferença entre mestiços e indubrasil. Individualmente, somente o componente omaso foi maior $(\mathrm{P}<0,05)$ nos mestiços leiteiros (valores expressos em kg). Entretanto, essa diferença não foi suficiente para alterar o valor do conjunto estômago. JORGE et al. (1999), utilizando os

Tabela 3 - Médias dos pesos de rins, baço, coração, pulmões, fígado e da língua, expressos em kg e em porcentagem do peso do corpo vazio (\% PCVZ), e coeficiente de variação (CV), em percentagem, em animais mestiço leiteiro e zebu, em fase de engorda.

\begin{tabular}{|c|c|c|c|c|c|c|}
\hline Itens & $\begin{array}{c}\text { Mestiços leiteiros } \\
\text { kg }\end{array}$ & $\begin{array}{l}\text { Indubrasil } \\
\qquad \mathrm{kg}\end{array}$ & CV\% & $\begin{array}{c}\text { Mestiços leiteiros } \\
\text { \% PCVZ }\end{array}$ & $\begin{array}{l}\text { Indubrasil } \\
\text { \% PCVZ }\end{array}$ & CV\% \\
\hline Rins & $0,830 \mathrm{a}$ & $0,697 \mathrm{a}$ & 11,25 & 0,217 a & 0,204 a & 10,05 \\
\hline Baço & 1,486 a & 1,404 a & 10,45 & 0,375 a & 0,362 a & 9,95 \\
\hline Coração & $1,699 \mathrm{a}$ & 1,459 a & 9,35 & 0,428 a & 0,374 a & 7,66 \\
\hline Pulmões & 2,877 a & $2,560 \mathrm{a}$ & 8,01 & 0,727 a & 0,656 a & 6,59 \\
\hline Fígado & 5,407 a & 5,138 a & 9,62 & 1,361 a & 1,323 a & 5,41 \\
\hline Língua & $1,183 \mathrm{a}$ & $1,055 \mathrm{~b}$ & 8,74 & 0,298 a & 0,273 a & 7,82 \\
\hline
\end{tabular}

Médias, nas linhas, seguidas de letras distintas são diferentes $(\mathrm{P}<0,05)$ pelo teste Tukey.

Ciência Rural, v.40, n.5, mai, 2010. 
Tabela 4 - Médias dos pesos de rúmen-retículo, omaso, abomaso, conjunto rúmen-retículo-omaso-abomaso (Estômago), mesentério e da gordura interna, expressos em kg e em porcentagem do peso do corpo vazio (\% PCVZ), e coeficiente de variação (CV), em percentagem, em animais mestiço leiteiro e indubrasil, em fase de engorda.

\begin{tabular}{|c|c|c|c|c|c|c|}
\hline \multirow[b]{2}{*}{ Itens } & Mestiços leiteiros & Indubrasil & & Mestiços leiteiros & Indubrasil & \multirow[b]{2}{*}{$\mathrm{CV} \%$} \\
\hline & & $\mathrm{kg}$ & CV\% & \% PCVZ & \% PCVZ & \\
\hline Rúmen-retículo & $6,797 a$ & $7,109 a$ & 7,07 & $1,714 \mathrm{a}$ & $1,828 \mathrm{a}$ & 6,14 \\
\hline Omaso & $2,947 a$ & $2,451 \mathrm{~b}$ & 15,58 & $0,745 a$ & $0,630 \mathrm{a}$ & 9,82 \\
\hline Abomaso & 1,033a & 0,963a & 7,87 & $0,261 \mathrm{a}$ & $0,300 \mathrm{a}$ & 6,56 \\
\hline Estômago & $10,777 a$ & $10,523 a$ & 9,45 & $2,720 \mathrm{a}$ & $3,159 a$ & 9,30 \\
\hline Mesentério & $16,157 a$ & $11,550 \mathrm{~b}$ & 11,83 & $4,061 \mathrm{a}$ & $2,982 \mathrm{~b}$ & 12,22 \\
\hline Gordura interna & 6,599a & $5,895 a$ & 8,49 & $1,659 a$ & $1,521 a$ & 7,39 \\
\hline
\end{tabular}

Médias, nas linhas, seguidas de letras distintas são diferentes $(\mathrm{P}<0,05)$ pelo teste Tukey.

grupos raciais Gir, Guzerá, Nelore e Tabapuã, também não observaram diferenças para o conjunto estômago entre os referidos grupos.

Em termos de gordura interna houve, em valores absolutos, maior deposição em animais mestiços leiteiros. Para gordura mesentérica, houve diferença significativa $(\mathrm{P}<0,05)$, sendo maior para os mestiços leiteiros. Isso comprova que animais mestiços leiteiros, em fase de engorda, depositam mais gordura internamente do que os animais indubrasil. PERÓN et al. (1993), utilizando vários grupos genéticos, observaram que animais mestiços leiteiros apresentam maior proporção de tecido adiposo localizado internamente, que os de raça de corte. Isso está de acordo com os resultados apresentados no presente trabalho. THOMPSON et al. (1983) também observaram que os animais mestiços leiteiros possuem maiores proporções de tecido adiposo localizado internamente do que animais mais especializados para corte. Essa maior proporção de gordura interna tende a aumentar a exigência de mantença dos animais mestiços leiteiros. Esse fato está de acordo com OWENS et al. (1993), os quais afirmam que os depósitos de gordura mesentérica e interna ocasionam maior exigência de mantença. Já PERÓN et al. (1993) afirmam que os animais zebuíno apresentam menores teores dessa gordura do que os animais taurinos ou mestiços leiteiros, sendo essa gordura metabolicamente mais ativa.

\section{CONCLUSÕES}

Animais indubrasil apresentam cabeça-péscouro mais pesado. Não existem diferenças quanto ao peso total de intestinos e órgãos entre indubrasil e mestiços leiteiros. Mestiços leiteiros possuem maiores teores de gordura interna.

\section{REFERÊNCIAS}

ALVES, D.D. Características de carcaça de bovinos zebu e cruzados holandês-zebu (F1), nas fases de recria e terminação. Revista Brasileira de Zootecnia, v.33, n.5, p.1274-1284, 2004. Disponível em: <http://www.scielo.br/scielo.php?script=sci_arttext\&pid=S151635982004000500020>. Acesso em: 22 dez. 2009. doi: 10.1590/ S1516-35982004000500020.

CARVALHO, P.A. et al. Componentes do peso vivo e órgãos viscerais de bezerros machos de origem leiteira ao nascimento, 50 e 110 dias de vida. Revista Brasileira de Zootecnia, v.32, n.6, p.1469-1475, 2003. Disponível em: <http:// www.scielo.br/scielo.php?script=sci_arttext \&pid=s151635982003000600022\&lng=pt\&nrm=iso>. Acesso em: $22 \mathrm{dez}$. 2009. doi: 10.1590/S1516-35982003000600022.

FERREL, C.L. et al. Estimation of body composition in pregnant and non pregnant heifers. Journal Animal Science, v.42, p.1158-1166, 1976.

JORGE, A.M. et al. Tamanho relativo dos órgãos internos de zebuínos sob alimentação restrita e “ad libitum”. Revista Brasileira de Zootecnia., v.28, n.2, p.374-380, 1999.

NATIONAL RESEARCH COUNCIL - NRC. Nutrient requirements of beef cattle. 7.ed. Washington, D.C, 1996. 243p.

OWENS, F.N. et al. Factors that alter the growth and development of ruminants. Journal Animal Science, v.71, p.3138-3151, 1993.

PERON, A.J; et al. Tamanho dos órgãos internos e distribuição da gordura corporal em novilhos de cinco grupos genéticos, submetidos à alimentação restrita e ad libitum. Revista Brasileira de Zootecnia, v.22, n.5, p.813-819, 1993.

SIGNORETTI, R.D. et al. Características quantitativas das partes do corpo não-integrantes da carcaça animal e desenvolvimento do trato gastrintestinal de bezerros da raça Holandesa alimentados com dietas contendo quatro níveis de concentrado. Revista Brasileira de Zootecnia, v.28, n.4, p.875-882, 1999.

Ciência Rural, v.40, n.5, mai, 2010. 
SILVA, F.F. et al. Consumo, desempenho, características de carcaça e biometria do trato gastrintestinal e dos órgãos internos de novilhos Nelore recebendo dietas com diferentes níveis de concentrado e proteína. Revista Brasileira de Zootecnia, v.31, n.4, p.1849-1864, 2002. Disponível em: <http:// www.scielo.br/scielo.php? script $=$ sci_arttext $\& \operatorname{lng}=$ p $\mathrm{t} \& \mathrm{nrm}=\mathrm{iso} \& \mathrm{t} \operatorname{lng}=\mathrm{pt} \& \mathrm{pid}=\mathrm{S} 1516-35982002000700029>$. Acesso em: 22 dez. 2009. doi: 10.1590/S151635982002000700029 .

THOMPSON, W.R. et al. Influence of body composition on energy requirement of beef cows during winter. Journal Animal Science, v.56, p.1241-1252, 1983.

UNIVERSIDADE FEDERAL DE VIÇOSA - UFV. SAEG Sistema de análises estatísticas e genética. Viçosa, MG, 1995. 75p. (Apostila).
VELOSO, C.M; et al. Composição corporal e requisitos energéticos e protéicos de bovinos $\mathrm{F}_{1}$ LimousinxNelore, não castrados, alimentados com rações contendo diferentes níveis de concentrado. Revista Brasileira de Zootecnia., v.31, n.3, p.1273-1285, 2002. Disponível em: <http://www.scielo.br/ s c i e lo.ph p ? s c ri pt = s ci_art text \& pid = S 1516 35982002000500028\&lng=en\&nrm=iso>. Acesso em: $22 \mathrm{dez}$. 2009. doi: 10.1590/S1516-35982002000500028.

VÉRAS, A.S.C. et al. Efeito do nível de concentrado sobre o peso dos órgãos internos e do conteúdo gastrintestinal de bovinos Nelore não castrados. Revista Brasileira de Zootecnia. v.30, supl 3, p.1120-1126, 2001. Disponível em: http:// www.scielo.br/scielo.php?script=sci_arttext\&pid=S151635982001000400029. Acesso em: 22 dez. 2009. doi: 10.1590/ S1516-35982001000400029. 